\title{
La literatura, el arte y el saber médico en Almas y cerebros de Enrique Gómez Carrillo
}

(gnacio Iriarte

Universidad Nacional de Mar del Plata - Conicet, Argentina

Recibido: febrero 2021 Aceptado: junio 2021

\begin{abstract}
Resumen
Las relaciones entre literatura y medicina constituyen uno de los temas centrales en la literatura de fines del siglo XIX. En este artículo me refiero a la cuestión a través de dos textos de Enrique Gómez Carrillo, publicados en Almas y cerebros: el cuento "Psicopatía" y el tratado "Notas sobre las enfermedades de la sensación desde el punto de vista de la literatura". En la primera parte, describo la importancia de la psiquiatría y el modo en que la literatura se sitúa en el campo de la enfermedad. En las partes segunda y tercera, comparo el tratado de Gómez Carrillo con Psycopathia sexualis, libro de Richard von Krafft-Ebing en el que se basa el escritor. En la última, extraigo algunas conclusiones referidas a las relaciones entre la literatura y la invención del psicoanálisis.
\end{abstract}

PALABRAS CLAVE: literatura, psiquiatría, enfermedad, normalidad, Gómez Carrillo

\section{Literature, art and medical knowledge in Almas y cerebros by Enrique} Gómez Carrillo

\begin{abstract}
The relations between literature and medicine constitute one of the central themes in the literature of the late nineteenth century. In this paper I present the issue through two texts by Enrique Gómez Carrillo, published in Almas y cerebros: the story "Psicopatía" and the treatise "Notas sobre las enfermedades de la sensación desde el punto de vista de la literatura". In the first part I describe the importance of psychiatry and the placement of literature in the field of disease. In the second and third parts, I compare Gómez Carrillo's treatise with Psycopathia sexualis, a book by Richard von Krafft-Ebing on which the writer is based. In the last part, I draw some conclusions regarding the relationship between literature and the invention of psychoanalysis.
\end{abstract}




\section{Literatura, arte e conhecimento médico em Almas e cérebros de Enrique Gómez Carrillo}

\section{Resumo}

As relações entre literatura e medicina constituem dos temas centrais da literatura do final do século XIX. Neste artigo, apresento o problema por meio de dois textos de Enrique Gómez Carrillo, publicados em Almas y cerebros: o conto "Psicopatía" e o tratado "Notas sobre las enfermedades de la sensación desde el punto de vista de la literatura". Na primeira parte, descrevo a importância da psiquiatria e a maneira como a literatura se situa no campo da doença. Na segunda e na terceira partes, comparo o tratado de Gómez Carrillo com Psycopathia sexualis, livro de Richard von Krafft-Ebing no qual o escritor se baseia. Na última parte, tiro algumas conclusões a respeito da relação entre a literatura e a invenção da psicanálise.

PALAVRAS-CHAVE: literatura, psiquiatria, doença, normalidade, Gómez Carrillo

\section{I}

En Almas y cerebros, miscelánea de textos publicada en 1898, Enrique Gómez Carrillo aborda varias veces la cuestión de la medicina. Por ejemplo, en el cuento "Piscopatía" el narrador presenta a un médico de la siguiente manera: "Esa tarde mis amigos se habían marchado ya, y en el café donde todos teníamos la costumbre de tomar el ajenjo, sólo quedaba el doctor Lariviere, un viejo fastidioso a quien yo no dirigía casi nunca la palabra" (33). A pesar de sus prejuicios, termina yendo a una consulta porque el médico lo convence de que tiene una grave enfermedad moral. Se sorprende de que Lariviere atiende en un lugar pobre, sin paredes que separen la sala de espera del lugar en el que trata a los pacientes. Todos son pintores o escritores notables, que el narrador conoce porque se trata de gente famosa. Cuando por fin consigue hablar con él, Lariviere le habla de una serie de casos, el primero de los cuales es un célebre pintor:

(...) su titilación cerebral es aguda y profunda, y le obliga a buscar matices que no existen en la naturaleza, a tratar de descubrir detalles invisibles, a combinar sus colores de manera que produzcan reflejos inverosímiles. ¿No ha visto usted su gran lienzo del 97? Esos prismas de luz filtrada y esas gamas complicadas de tonos fuertes sobre tonos pálidos bastarían para asegurar que el autor está gravemente enfermo de titilación, de "vicio supremo" como diría ese grafómano de Peladán. Y además este mal se complica en él con satiriasis ideológica, como lo indica el cuerpo desnudo, cubierto de pompas de jabón, de su figura principal, al lado del cuerpo de la negra, desnudo también y hecho con amor y con entusiasmo doloroso. (39-40)

A los ojos de Lariviere, los cuadros del pintor son una colección de síntomas que es necesario explicar. De su comentario casi podríamos decir que partió de una división entre forma y contenido. Por una parte el pintor sufre de "titilación cerebral", lo que lo lleva a producir colores y matices que no se encuentran en la realidad, mientras que en el plano del contenido las figuras desnudas lo llevan a diagnosticarle satiriasis, es decir, adicción al sexo. No contento con esta demostración de sus competencias, Lariviere expone algunos casos de escritores que también han caído en perversiones 
sexuales, deteniéndose especialmente en René Vincy. El narrador se sorprende: ¿se trata del "autor del Sigisbeo, el poeta que fue casi genial en su primera obra, que trató de suicidarse y que ahora escribe novelas ridículas, dignas de Jorge Honet?" (43) (se refiere al exitoso novelista George Ohnet, de la ya vieja escuela naturalista). Efectivamente es él:

¿Se acuerda usted de las circunstancias de su tentativa de suicidio? Pues bien: como entonces era yo el médico de su familia, me llamaron, y le salvé físicamente, y más tarde le salvé también intelectual y moralmente... ¡Pobrecillo! Su amigo Larcher le había llenado de locuras el cerebro. Yo eché al fuego todos sus manuscritos y durante la convalecencia no le permití que leyese sino libros sanos, las obras de Laviche, de Sarcey, de Jorge Sand; luego le aconcejé [sic] que escribiera novelas equilibradas. Y allí le tiene usted, gracias a mi régimen, siendo un literato digno de competir con el autor de Sergio Panine. (43-44)

Ante semejante exposición, el narrador se convence de que no va a volver, como dice al final del relato: "¿A qué había de volver? ¿A que me curase, convirtiendo mi locura en idiotez? No; yo he tomado ya mi determinación definitiva; y puesto que en el mundo de las letras es necesario escoger entre la Burguesía y la Enfermedad, me quedo con la Enfermedad" (44).

El tema del cuento resulta familiar a los lectores del siglo XIX. Desde el naturalismo la figura del médico cumple un papel central en cuentos y novelas. En aquella escuela ese personaje representa una fuente de racionalidad y certeza y constituye, además, un modelo para el escritor, como podemos ver en "La novela experimental", ensayo en el que Emile Zola toma la Introduction à $l$ étude de la médecine expérimentale, de Claude Bernard, para trasponer su método al campo de la novela. ${ }^{1}$ Pero en Gómez Carrillo el médico tiene una función distinta: representa una normalidad de la que el arte debe escapar. Esa normalidad, como destaca el narrador en la disyuntiva final, está asentada en la burguesía.

No se trata de una caracterización gratuita. Como recuerda Benigno Trigo, existe una continuidad importante entre la medicina, la normalidad y la burguesía, debido a que la psiquiatría, en el siglo XIX, se forjó convirtiendo los valores de la burguesía en la forma misma de la normalidad. Klaus Doerner destaca que la contribución de Phillipe Pinel, el padre de la psiquiatría francesa, fue "la transferencia de valores burgueses (como la responsabilidad del individuo, el fondo moral, la familia, y la propiedad) al discurso científico, y a la práctica psiquiátrica", de modo que la "definición pinelieana de la locura como una enfermedad no sólo fisiológica, sino también moral, surgió a raíz de esa transferencia" (Trigo, 1994: 134). Con la medicina, los valores de la burguesía forman un código victoriano que regula las subjetividades desde una fundamentación científica. En este aspecto, la figura del psiquiatra tiene mayor alcance que el Estado o las leyes, porque si bien estos también imponen los valores de la burguesía como condiciones previas a la vida en sociedad, pueden ser puestos en discusión, mientras que la medicina justifica estas posiciones por medio de leyes científicas en extensos tratados que se publican bajo el amparo del saber objetivo y la autoridad que de él emana. El médico constituye un ordenador de los discursos y los comportamientos, con el agregado de que se presenta como una instancia científica $y$, por lo tanto, justifica sus prescripciones a partir de una racionalidad que tiende a naturalizar los patrones de conducta que postula bajo la idea de la salud.

1 En ese conocido ensayo, Zola afirma lo siguiente: “Sólo tendré que hacer un trabajo de adaptación, ya que el método experimental ha sido establecido con una fuerza y una claridad maravillosas por Claude Bernard en su Introduction à l'étude de la médecine expérimentale" (41). Incluso llega a declarar que "A menudo me bastará con remplazar la palabra 'médico' por la palabra 'novelista' para hacer claro mi pensamiento y darle el rigor de una verdad científica” (41-42). 
Las críticas de Lariviere a pintores y escritores proyectan una defensa implícita de los valores de la vida burguesa. ¿Qué hay más victoriano que la condena de un cuadro a causa de lo que revela en términos de sexualidad? En igual sentido, la titilación cerebral manifiesta una propensión hacia los colores irreales en los que se revela una pérdida de relación con la realidad. Lo mismo vale para las afirmaciones que hace sobre Vincy. Cuando lo salva del suicidio, descubre que tiene el cerebro lleno de locuras, lo que lo lleva a administrarle una serie de escritores que califica como sanos. A la vez, sus esfuerzos tienen el resultado de transformar su obra en una continuación o una copia del exitoso escritor naturalista Ohnet.

Si el narrador de Gómez Carrillo prefiere la enfermedad es porque establece una identificación implícita entre lo que es estéticamente raro, y por consiguiente novedoso, y lo que se encuentra en los márgenes de la normalidad psicológica y social. En una crónica sobre Jean Lorraine, también recopilada en Almas y cerebros, sostiene lo siguiente:

De 1860 a 1896, en efecto, el gusto ha cambiado casi radicalmente. Cuando los precursores del naturalismo artístico comenzaron a escribir, lo "raro" era el japonismo, el prerrafaelismo y el wagnerismo. Hoy las estampas de Outamaró, los lienzos de Boticelli y las óperas de Wagner, son tan conocidas como las cabezas de Rafael y las sinfonías de Rossini, por lo cual Lorrain ha tenido necesidad de buscar sus extraños ideales en fuentes menos popularizadas y más capaces de producir sorpresas estéticas. $(127)^{2}$

Esta búsqueda de lo raro es característica de Gómez Carrillo y de la época en general. No se trata de abandonar una herencia que se reconoce falsa; al contrario, lo que se ha impuesto se considera falso porque es lo heredado y lo normal. En Lorraine, no se llega a la novedad por medio de un trabajo exclusivamente literario, sino que es necesario realizar experiencias con la percepción y los márgenes de la vida. Como revela Gómez Carrillo, el escritor encontró la rareza que buscaba en la droga y el crimen, gracias a los cuales publicó Contes d'un Buveurd'Ether y una serie de cuadros sobre los márgenes titulado Du bord de l'eau.

La defensa de la enfermedad por parte del narrador de "Psicopatía" se entiende en esa clave. Si el médico defiende la normalidad burguesa, el arte debe colocarse del lado de la enfermedad y lo pecaminoso, recorrer los márgenes de la ciudad, ahí donde el vicio se cruza con los placeres, donde se reúne la corte del lumpenproletariat, los despojados y desplazados. Ese programa literario se inicia con el modernismo, se metamorfosea en el surrealismo, tiene momentos de esplendor en la Beat Generation, llega hasta el neobarroso de Néstor Perlongher, tan modernista a su modo. Pero a fines del siglo XIX esa forma de pensar la literatura mantiene todavía una relación compleja con la psiquiatría, hecha de ambivalencias, miradas cómplices y desconfianzas mutuas. Haríamos mal en creer que Gómez Carrillo descarta la medicina. Como muchos otros escritores de la época, se siente fascinado por ella; y más importante aún, la necesita: sin medir exactamente lo que ella plantea como normalidad, no podría pensar su obra como discurso que ocupa sus sombras y los huecos que deja su racionalidad. El narrador de "Psicopatía" decide no volver al consultorio de Lariviere. Pero para reconocerse en el polo opuesto a lo burgués tuvo que hablar durante todo el cuento de la medicina. El lugar del arte solo es pensable en relación con la psiquiatría.

2 Aunque no es objeto de este texto, no quisiera dejar pasar que Gómez Carrillo dice que el prerrafaelismo se ha vulgarizado el mismo año en que José Asunción Silva lo hace suyo como la quintaescencia del gusto para escribir De sobremesa. 


\section{II}

El programa implícito de "Psicopatía" tiene dos direcciones. La primera es identificar la normalidad por medio de una descripción de la psiquiatría, y la segunda es colocar la literatura en el espacio de la enfermedad. En Almas y cerebros, el texto más sistemático en el que Gómez Carrillo realiza esas dos operaciones es "Notas sobre las enfermedades de la sensación desde el punto de vista de la literatura".

Colocado estratégicamente como cierre el libro, las "Notas" constituyen un tratado sobre el sadismo, el masoquismo, el fetichismo y la inversión sexual. ${ }^{3}$ Lejos de descartar la psiquiatría, Gómez Carrillo declara que, para redactarlas, ha estudiado las principales autoridades en la materia. Al principio de su texto cuenta que Max Nordau, a quien le dedica una favorable crónica que también recoge en Almas y cerebros, y a quien llama "mi ilustre amigo", le recomienda la lectura de Psycopathia sexualis, de Richard von Krafft-Ebing, con el propósito de "conocer la fuente de todo lo extraordinario de la novela moderna" (327). Gómez Carrillo asegura que también leyó obras afines: "leí la Dinamogenia General de Binet, leí La Locura de Legrand, leí Los Bisexuados de Laurent, leí El Hombre de Genio de Lombroso" (327).

De todos estos libros que dice que leyó, existe uno que es indudable que estudió con detenimiento: Psycopathia sexualis. De hecho, las "Notas" pueden comprenderse como una especie de resumen del extenso tratado de Krafft-Ebing. ${ }^{4}$ De él toma las cuatro categorías de perversiones de las que se ocupa e incluso lo sigue tan al pie de la letra que mantiene el orden que propone el psiquiatra en su volumen: sadismo, masoquismo, fetichismo e inversiones sexuales. Por otra parte, todos los casos reales que cita Gómez Carrillo, desde algunos breves sobre hombres que asesinan mujeres a otros extensos referidos al fetichismo y al travestismo femenino, son traducciones de los que presenta Krafft-Ebing, quien a su vez toma varios de otros autores.

Por supuesto, esto no significa que Gómez Carrillo copie todo lo que aparece en Psycopathia sexualis. Por el contrario, elabora una serie de operaciones sobre el libro de Krafft-Ebing que suponen una profunda transformación. En primer lugar, la obra del psiquiatra es un volumen monolítico y rigurosamente estructurado. Empieza con un capítulo extenso, "Fragmentos de un sistema de psicología de la vida sexual", en el que se refiere a la importancia del sexo como causa para comprender los comportamientos y aun las formas sofisticadas de la cultura. Escribe en un momento que "El factor sexual también ejerce una gran influencia en el desarrollo del sentido estético. ¡Qué serían de las bellas artes y la poesía sin el componente sexual!" (13). Luego expone lo que considera una vida sexual normal, lograda gracias al avance del cristianismo: "que ha elevado a las mujeres al nivel social de los hombres y que ha transformado el pacto de amor entre hombres y mujeres en una institución religiosa y moral" (5), lo que lo lleva a concluir que "el amor del hombre, a medida que avanza la civilización, sólo puede tener un carácter monógamo y debe basarse en un contrato duradero" (5-6). Presenta, además, una serie de consideraciones sobre la enfermedad y expone varias observaciones acerca de los momentos históricos en los que se incrementan las perversiones, momentos que juzga como decadentes y afeminados. A continuación coloca dos capítulos en los que estudia los componentes fisiológicos

3 Uso “inversión sexual” porque es el concepto que emplea Gómez Carrillo. Como revela Oscar Montero (1997), la palabra "homosexual" se crea en alemán a mediados del siglo XIX y recién empieza a circular en otras lenguas en el siglo XX. Vale decir que, a diferencia de Gómez Carrillo, Krafft-Ebing la emplea de manera usual.

4 La primera edición de Psycopathia sexualis es de 1886. En 1892, se publica la traducción al inglés de Charles Gilbert Caddock. En 1895, aparece la edición en francés, traducida por Émile Laurent y Sigismond Csapo. En ambas traducciones, el texto no está completo. Este sí se encuentra en la doceava edición en inglés, de 1939. En todos los casos, y salvo excepciones expresamente señaladas, traduzco las citas siguiendo la edición en francés de 1895, por tratarse de una edición que seguramente manejaba Gómez Carrillo. 
y antropológicos de la vida sexual. Los últimos tres están dedicados a las patologías: "Patología general", "Patología especial" y "Aspectos legales de la patología sexual".

En línea con el programa del cuento "Psicopatía", Gómez Carrillo suprime la mayor parte de esta exposición sistemática y bien organizada. Primero deja de lado toda la presentación de Krafft-Ebing sobre la normalidad sexual. Luego hace una serie de observaciones sobre el amor que tienen el propósito de demostrar que en realidad las formas normales y saludables no existen de ninguna manera:

\begin{abstract}
Lo que en literatura se llama "amor sano" no existe en la Naturaleza o por lo menos no existe como tal amor. El amor sano, el que no hace sufrir y gozar al mismo tiempo, el que conserva un juicio cabal, no es, en realidad, sino una amistad cariñosa e instintiva que tiene por base filosófica el sentimiento de la perpetuación de la especie. (328)
\end{abstract}

Incluso el final de esta cita manifiesta un corte abrupto con las propuestas de KrafftEbing, porque este hace surgir la normalidad precisamente de la orientación a perpetuar la especie. Para Gómez Carrillo nada de eso tiene interés, porque lo que le importa es el amor pasión: "El amor pasión, en cambio, ha inspirado las más bellas páginas de la literatura contemporánea" (328), y lo comprueba citando a Michelet, Stendhal y Baudelaire, asegurando que las Flores del mal "son un verdadero Breviario de los sufrimientos pasionales" (328). En línea con esto, suprime los capítulos sobre las observaciones fisiológicas, pasa por alto las exposiciones anatómicas, descarta los casos de patologías especiales y omite las consideraciones legales de las patologías. Si leemos su texto en relación con el tratado de Krafft-Ebing, podemos decir que Gómez Carrillo enfoca una zona bien acotada y definida: la zona en la que el psiquiatra expone las patologías generales. E incluso en ese capítulo descarta y modifica nombres y cambia los sentidos. Krafft-Ebing compone un árbol conceptual sistemático conformado por categorías técnicas que están en un riguroso y científico latín. Asimismo, clasifica de acuerdo con la procedencia de las patologías: están las que son causadas por algún problema corporal y están por otro lado las que designa con el nombre de "Neurosis cerebrales". Dentro de estas, ordena las afecciones en Paradoxia, Anestesia, Hyperesthesia y Paraesthesia. Gómez Carrillo enfoca con precisión: elimina todo el árbol y se queda con esta última categoría. De este modo, convierte Psyopathia sexualis en un catálogo de relatos escabrosos e interesantes situados en el campo del sadismo, el masoquismo, el fetichismo y la inversión sexual. Nada refleja mejor esta actitud que el cambio de nombre con el que designa este conjunto conceptual. En Krafft-Ebing son nombradas con el categórico "perversiones". Para Gómez Carrillo, esas "perversiones" son la forma natural de los sentimientos humanos, y por eso las designa como "amor-pasión".

\section{III}

En sus cuadros basados en cómics, el pintor pop Roy Lichtenstein tomaba una viñeta, la recortaba y, copiando las mismas técnicas empleadas en el original, le daba grandes dimensiones. Salvando las distancias temporales, estéticas y conceptuales, la operación que Gómez Carrillo realiza sobre Krafft-Ebing es similar: toma los relatos de la enfermedad y los hace ocupar todo el texto. De este modo reivindica la unión de la literatura con la enfermedad, lo que significa que convierte la psiquiatría en un marco teórico-narrativo que le sirve para contar historias inmorales y defender en acto la relación de la literatura con los comportamientos considerados anormales. El esquema que sigue en cada categoría es siempre el mismo: compone una presentación general de la pasión con una información mínima, cita alguna autoridad psiquiátrica y luego cuenta o reescribe historias que hacen comprensible el sentimiento en cuestión. Por este medio, abandona el análisis psiquiátrico y convierte su texto en un catálogo de historias anormales. 
El ejemplo característico es el que sigue con el sadismo. Gómez Carrillo aborda ese comportamiento a través de algunas reflexiones propias y una cita extensa de Schaefer. En esa presentación se refiere a la antigüedad del sentimiento erótico de la crueldad, señalando que se trata de un instinto primitivo. Luego transcribe las historias de Barba Azul, el marqués de Sade y algunos casos reales. Presenta las historias extensas a la manera en la que Borges narrará sus relatos en Historia universal de la infamia. Es decir, en muchos casos son biografías o relatos recontados. Por ejemplo, en el primer tramo relata la vida de Gil de Laval, barón de Retz y señor de Montfort, que después dio forma a Barba Azul. Se trata de un ejercicio de escritura preciso, con un estilo ajeno al preciosismo modernista, con buen apoyo documental. Carrillo narra una historia cohesiva y equilibrada, compone personajes y repone diálogos y busca establecer una intriga, a pesar de que se trata de una historia conocida. Narra con pormenores el momento en el que el demonio lo vuelve su servidor, transformando su barba roja en azul. Luego se detiene en las misas negras, en las que asesina niños y mujeres: "En menos de cinco años fueron degollados y hechos materialmente pedazos, en el castillo de Tiffauges, unos ciento cincuenta niños y hasta cien mujeres" (337). Escribe más adelante:

\begin{abstract}
Al principio el mariscal no mataba a sus víctimas sino para extraerles las entrañas y ofrecerlas en holocausto a Satanás; pero más tarde, cuando su paciencia comenzó a cansarse de esperar en vano al ser Todo Poderoso en el Mal que debía revelarle los secretos del goce infinito y de la riqueza inagotable, sus crímenes tuvieron por verdadero objeto apagar su sed de crueldad voluptuosa. (338)
\end{abstract}

Lo más notable de la cita es el interés que Gómez Carrillo pone en las motivaciones criminales de Barba Azul. Primero se refiere a su comportamiento por medio de una explicación que, si bien es sobrenatural, no deja de darle una causalidad nítida a sus acciones: mata a sus víctimas para extraerles las entrañas y ofrecérselas a Satanás. Independientemente de lo que podamos pensar de ese tipo de explicaciones, pone en claro que Barba Azul realiza sus crímenes para lograr un fin determinado. Pero luego el deseo se independiza de esas motivaciones y se vuelve una causa en sí mismo. Como dice Gómez Carrillo, Barba Azul se cansa de esperar algo del más allá, de modo que los crímenes se transforman en un modo de apagar su sed voluptuosa. Esa independencia de toda causa externa le da morbosidad a sus comportamientos y deseos. En el mismo párrafo, Gómez Carrillo afirma que Barba Azul da un paso más en su perversión dilatando la agonía de sus víctimas:

En general los niños y las mujeres que caían entre sus garras no morían sino después de haber servido durante algún tiempo como instrumentos de exaltación voluptuosa. A veces el barón comenzaba por hacerles pequeñas heridas para introducir en ellas los dedos o la lengua. En otras ocasiones cortábales un brazo con el cual les azotaba después, mientras su amigo, el sacerdote italiano, lamía la sangre de la llaga. Cuando una de sus víctimas mostraba una fuerza de vitalidad extraordinaria, Gil de Retz le ofrecía la mitad de su lecho para oírla agonizar en el silencio de la noche y para acariciar, tranquila y largamente, sus miembros ablandados y humedecidos por el dolor y la sangre. (338)

En otro tramo de su texto se detiene en la figura de Sade. En él realiza una operación crítica muy interesante. Por una parte, hace una lectura poco favorable de Justine, Juliette y Los crimenes del amor. Lo que dice de la primera vale para las tres (y en realidad para todas las obras del autor): "Las escenas sanguinarias y obscenas que forman el fondo de la obra, son, en efecto, de un diabolismo inconcebible; pero abundan de tal modo y se repiten tan a menudo, que el lector llega a no ver en ellas sino un panorama monótono, delirante y falso" (345-346). Con equivalente desinterés se detiene en la "parte filosófica del libro": "nada tan inocente y aun tan simple. El marqués de Sade se proponía probar que la virtud conduce a la desgracia. Y para apoyar su tesis con 
todos los argumentos de que podía disponer, escribió más tarde una continuación a Justina, titulada Julieta" (346), en la que asegura que "sólo por medio del vicio puede llegarse a la ventura perfecta" (346).

Frente a ese monótono panorama, Gómez Carrillo destaca el interés que representa su vida. Adhiere a la leyenda negra de Sade señalando que su biografía "es una verdadera odisea de libertinaje" (347). Es cierto que esa odisea en realidad no fue tal. Como recuerda Guillaume Apollinarie, las anécdotas que circulan alrededor de su vida se levantaron con algunos datos presumiblemente reales y mucha atmósfera tomada de su literatura. ${ }^{5}$ De hecho, Gómez Carrillo encuentra algunos horrores, pero son pocos: secuestra y azota a Rose Keller, seduce a su cuñada y la pasea por Italia a la vista de todos, da una cena que aparentemente termina en una orgía con algunas mujeres muertas y no mucho más. De todos modos, lo que interesa es ese quiebre por medio del cual desplaza unas obras que considera más bien abstractas por una vida, y más que una vida, por una figura apasionante por la singularidad y la pasión criminal. Escribe en un tramo de su relato, explicando el quiebre de su vida:

Al cabo de algunos meses de vida conyugal, el marqués de Sade comprendió que su alma era demasiado inquieta para vivir atado a otra alma y que sus nervios necesitaban sacudimientos más intensos que los que una burguesa honesta y enamorada podía proporcionarle. En pleno período de luna de miel, abandonó, pues, a su esposa y se refugió, acompañado por una bailarina del teatro de la Comedia, la célebre Beauvoisin, en su palacio de Comptat.

Pero tampoco los besos complicados de las cortesanas bastaban a llenar sus deseos. Su complexión psíquica tenía necesidad de algo que fuese extraordinario, de algo que todos los ricos hombres de su tiempo no pudieran hacer, de algo, en fin, que no se pareciese a los placeres monótonos de los cortesanos parisienses. (343)

La vida se une a la literatura en la búsqueda de lo raro. Sin afirmarlo de esta manera, Sade se convierte en una figura heroica porque afronta a los ojos de Gómez Carrillo el dilema que se plantea el narrador de "Psicopatía" cuando escucha la exposición de casos que realiza Lariviere: la disyuntiva es entre la burguesía y una forma del arte que coincide con la enfermedad. A fines del siglo XVIII, Sade mostraba el camino: abandona las normas conyugales, aburrido también de esa otra actividad del burgués que son las amantes, para dedicarse al crimen. Sade expresa una transformación vital que Gómez Carrillo en la literatura: en "Notas" también abandona la normalidad burguesa, suprimiendo toda la parte normalizadora del tratado de Krafft-Ebing, y levanta la singularidad de las pasiones.

Esta colocación se encuentra plasmada en la exposición de casos reales. Glosa varios de Krafft-Ebing, quien a su vez los toma de otros autores. En el ámbito del sadismo repone un caso de Lombroso: un hombre mata a la mujer que ama, luego a su padre, sus dos hermanos y finalmente empieza a matar bueyes porque no le quedan humanos que asesinar. Transcribe otro de la zona de Alemania (Krafft-Ebing lo extrae de Feurbach): un joven se encuentra cierta vez con su amada y en "el delirio de su pasión" la corta "en pedazos, tratando de imitar a los carniceros; cuando el cuerpo de su víctima estuvo dividido como el de un carnero, comenzó a comerse los trozos que más blandos le parecían" (342). En el campo del masoquismo cita una parte entera de las

5 Escribe Apollinaire: “Se sabe que nunca fue loco ni maníaco. Los relatos de Jules Janin y la anécdota que narra Victorien Sardou, que representa al marqués de Sade haciéndose llevar rosas a Bicêtre y mojando estas en el cieno hediondo de un arroyuelo (...) aparecen como otras tantas leyendas, que quizá tengan un fondo de verdad, pero que han sido transformadas a gusto y paladar por la imaginación de aquellos que, al leer Justine y no comprender su sentido ni su alcance, no pudieron imaginar al autor diferente de un loco ahíto de manías criminales y asquerosas" (19). 
Confesiones de Jean-Jacques Rousseau en la que cuenta el momento de su infancia en el que descubre la voluptuosidad que le produce ser castigado. De nuevo es lo singular: un hombre mata a toda una familia, un joven se come a su novia por las partes más blandas, un pensador famoso registra el momento precioso en el que Lambercier le da su primer castigo. Carrillo agrega a este catálogo el relato del segundo acto de Venecia salvada, la obra de teatro de Thomas Otway, de 1682: un senador llamado Antonio va a casa de una cortesana, se pone en cuatro patas $y$, tras comunicarle que desea ser un perro, le pide que lo patee. La mujer azota "al viejo libidinoso que se arrastra a sus pies, que grita, que babea y que se retuerce, agonizante de goce, jadeante de satisfacción, en espasmos de placer doloroso" (362).

"Notas" coloca la literatura en el campo de la enfermedad. Relatos en primera persona, acciones puntuales, nombres de personas, acontecimientos que brillan por su singularidad. De este modo, ampliando la enfermedad, tergiversa los propósitos de la psiquiatría: si acepta, con Krafft-Ebing, que todo lo que hacen los hombres y las mujeres es resultado del sexo, la literatura vale, no porque busque deseos normales, sino porque decide habitar lo anormal dándole una palabra a esos deseos. En una parte de Psycopathia sexualis, Krafft-Ebing sostiene lo siguiente sobre Leopoldo von Scher-Masoch: "siempre que eliminó su perversión de sus esfuerzos literarios fue un escritor talentoso, y como tal habría alcanzado una verdadera grandeza si se hubiera dejado llevar por sentimientos sexuales normales" (132-133). ${ }^{6}$ Esa afirmación no se encuentra en las traducciones al inglés y al francés de fines del siglo XIX, por lo que es probable que Gómez Carrillo no la haya leído, pero resumen el sentido de la exposición que el psiquiatra hace sobre el masoquismo y sus constantes envíos a la literatura. En "Notas", Gómez Carrillo toma la dirección opuesta al mostrar el interés literario que tienen esos instintos que caen fuera de lo que se considera normal.

Entre el excelente relato de Rousseau y los casos reales hay diferencias sustanciales en cuanto al estilo y la realización. Pero sean sintéticos o extensos, en tercera o en primera persona, prolijos o desprolijos, todos constituyen relatos en potencia que parecen aguardar un desarrollo mayor. En el momento en el que habla de masoquismo, relata una anécdota real que le contó Oscar Wilde. El Lord X es durante años un don Juan. Cuando se aburre de las mujeres londinenses busca otras en India, Egipto y Senegal. Todas, finalmente, terminan cansándolo por igual. Tras descubrirse de esa forma hastiado, intenta darse muerte con un puñal. Falla, pero la herida le produce "una sensación tan agradable, un deseo tan intenso" que renuncia de inmediato al suicidio (355). Entonces se convierte en espadachín para recibir heridas, luego pone una academia de box y de esgrima para mujeres con el propósito de que estas lo corten y lo golpeen. Goza durante buen tiempo hasta que una alumna robusta, después de darle un beso, le propone un asalto con floretes verdaderos, que concluye con una herida mortal, que ocasiona la muerte del lord. Oscar Wilde le advierte, sin embargo, que la herida no era mortal: el hombre sucumbió por el placer que sintió al recibirla después de haber sido besado.

Oscar Wilde termina el relato diciéndole que piensa utilizar la anécdota para escribir una novela. De esta forma sutil, Gómez Carrillo muestra el destino potencial que se encuentra en las narraciones que colecciona en su tratado.

\section{IV}

Como acabamos de ver en "Psicopatía" y "Notas", y antes en la crónica favorable que realiza sobre Max Nordau, el escritor mantiene una relación compleja con la psiquiatría. 
Por una parte valora ese campo del saber, mientras que por el otro coloca la literatura del lado de la enfermedad. Lo mismo podemos decir de otros escritores. El caso de Asunción Silva es ilustrativo en este sentido. Refiriéndose a De sobremesa, Alfredo Villanueva Collado sostiene que Asunción Silva descarta la psiquiatría de manera tajante. ¿Pero es así? En líneas generales, podemos afirmar que la novela está compuesta por el diálogo de José Fernández con cuatro médicos, Oscar Saenz, Max Nordau, John Rivington y Charvet. En esos diálogos se aborda un conjunto numeroso de temas, como el arte, la religión, la poesía, la figura de la mujer e incluso la posibilidad de poner en marcha emprendimientos comerciales. Sin embargo, lo interesante es que aparecen en el marco de una conversación, y en muchos casos de una consulta, del narrador con los psiquiatras. Como revelaron autores como Oscar Montero y Silvia Molloy, la novela plantea un deseo irreductible que podría comprenderse como un deseo homosexual. Nadie lo afirma de una manera expresa, no hay palabra en castellano que pueda nombrar eso. Sin discutir que se trate de un deseo homosexual, se puede acentuar ese carácter difuso, señalando que se trata de una singularidad sin nombre, que puede ser muchas cosas a la vez. Precisamente, esa singularidad solo se puede intuir en la relación dialéctica del sujeto con el discurso normalizador de la psiquiatría. Por eso ese campo del saber sigue siendo central en la literatura de fines del siglo XIX: si ha dejado de ser infalible, empieza a valer por las fisuras que lo recorren, porque esos agujeros muestran el deseo singular que sostiene a los sujetos. Si los textos de Asunción Silva o Gómez Carrillo mantienen un diálogo con los psiquiatras, no es solo por lo que tienen para decir, sino también porque ese diálogo les permite trazar una dialéctica mediante la cual la literatura se coloca en aquello que ese discurso no puede decir.

Los textos de Gómez Carrillo que acabo de comentar permiten profundizar en esta idea. En "Psicopatía" el narrador no podría pensar la literatura sin las observaciones, si se quiere ridículas, del psiquiatra. Y de manera más extensa, vale recordar que lo raro, ese valor clave de fin de siglo, es una condición tan histórica y relativa, que solo puede aparecer en los márgenes de la normalidad. En sus textos, Carrillo rechaza la faz normalizadora de la psiquiatría, cuestión que es visible en que el escritor suprime la exposición que al respecto hace Krafft-Ebing, pero en las "Notas" busca habitar literariamente aquellos deseos que la psiquiatría identifica. Esa apuesta también se puede percibir en la constante referencia del escritor a lo singular. Sade, Masoch, Rosusseau, el fetichismo y la inversión sexual son formas de una singularidad que constituye para el escritor la quintaesencia del arte y la literatura. Nada es más revelador, en este sentido, que la crónica sobre Jean Lorraine. Aunque en ella no se refiere a los deseos sexuales, manifiesta un sentido muy preciso de lo que está codificado como normal y aquello que escapa como lo raro. El punto de fuga del arte es lo ilegal: la droga y el crimen.

El interés de las "Notas" se encuentra en que manifiesta que la literatura tiene que habitar lo que la psiquiatría condena. Y como acabamos de ver, no se trata de una cuestión declarativa, sino de una posición que el propio Gómez Carrillo pone en práctica al convertir el tratado en un catálogo en el que se exponen literariamente los deseos. Este movimiento de la literatura con la psiquiatría se plantea como una dialéctica que debe comprenderse como central en la época, porque lo que muestra la literatura, con y contra la psiquiatría, es una interrogación que, bajo otros términos, se produce con la invención del psicoanálisis por parte de Sigmund Freud. Como dice Jacques Lacan, la revolución de Freud se encuentra en que se preguntó por el deseo. En lugar de buscar una voluntad normalizadora, que era clave en la psiquiatría a la manera de Krafft-Ebing, lo que hizo fue preguntarse por el deseo y hacerlo hablar. Lacan lo sintetizó por medio de la fórmula freudiana "Wo es War, soll Ich werden". No hay que normalizar el inconsciente por medio del yo, sino escuchar lo que este tiene para decir. ${ }^{7}$ 
La literatura precede ese movimiento. Para Gómez Carrillo, escribir es ir ahí donde está la enfermedad, el crimen, la locura y la droga, porque allí se encuentra la verdad del ser humano. En "Notas" escribe lo siguiente:

El sadismo no es sino la exaltación morbosa de uno de los instintos más naturales del hombre: el instinto de la crueldad.

Todos, en efecto, llevamos en el fondo de nuestras almas una fiera que duerme encadenada a veces por la piedad, a veces por la timidez, a veces por la religión-. Cuando esa fiera despierta, tenemos necesidad de contemplar el sufrimiento ajeno para lograr el propio goce. (330-331)

Lo notable es que Gómez Carrillo manifiesta que esta es la verdad primitiva del hombre, es decir, lo que se opone al artificio. Aquello que la psiquiatría descarta como anormal es lo que la literatura descubre como la verdad del ser humano. Notemos el giro que da en este sentido:

Y no se diga que la crueldad es un sentimiento de refinados, pues, por el contrario, nada hay de menos "humanitario" en el sentido falso que a esta palabra se da, que el hombre natural, entregado a sus sentimientos. Todas las razas primitivas fueron crueles. El goce ante el dolor ajeno, es un sentimiento innato en el hombre. Lo artificial y lo refinado, sería más bien la sensibilidad humanitaria, en caso de que un sentimiento cualquiera pudiese ser artificial. (331)

Mariano Siskind y Hanno Ehrlicher han destacado la importancia de la colocación de Carrillo en las redes mundiales. Esto tiene una doble dirección: habla del impacto de lo mundial en el escritor, pero también de que Carrillo participa de ese diálogo global. Podemos decir que la relación ambivalente que produce entre la literatura y la psiquiatría, basada en un diálogo con Krafft-Ebing, se explica de ese modo: ancla su obra en una problemática global sobre el sujeto, la normalidad y la modernidad que va a articularse bajo la forma de la invención del psicoanálisis freudiano. En la misma línea, revela la importancia de la literatura como un discurso que durante buena parte del siglo XX va a estar en el foco de los interrogantes sobre el deseo, la locura y los límites del ser humano. 


\section{Q Bibliografía}

»Apollinaire, G. (1999). Introducción. En Sade, Obras completas. Buenos Aires, Corregidor.

»Ehrlicher, H. (2015). Enrique Gómez Carrillo en la red cosmopolita del modernismo. Iberoamericana, № 60: 41-60. Ibero-Amerikanische Institut Preußischer Kulturbesitz

» Gómez Carrillo, E. (1898). Almas y cerebros. Historias sentimentales, intimidades parisienses, etc. París: Garnier Hermanos.

» Krafft-Ebing, R. Von (1886). Psychopathia sexualis. $1^{\underline{a}}$ ed. Stuttgart, Verlag Von Ferdinand Enke.

» Krafft-Ebing, R. Von (1895). Psychopathia sexualis. París: Georges Carré.

»Krafft-Ebing, R. Von (1939). Psychopathia sexualis. Londres: William Heinemann.

» Lacan, J. (1991). La cosa freudiana o el sentido del retorno a Freud en psicoanálisis. En Escritos 1, cap 17. Buenos Aires: Siglo XXI.

"Molloy, S. (2012). Poses de fin de siglo. Desbordes del género en la modernidad. Buenos Aires: Eterna Cadencia.

»Montero, O. (1997). Escritura y perversión en De sobremesa. Revista Iberoamericana, № 178-179. Pittsburgh, University of Pittsburgh.

»Montero, O. (2019). Erotismo y representación en Julián del Casal. Leiden: Almenara.

» Siskind, M. (2016). En viaje a Oriente: Gómez Carrillo y la cuestión judía. En Sueños cosmopolitas. Modernidad global y literatura mundial en América Latina, cap. 5. Buenos Aires: Fondo de Cultura Económica.

»Trigo, B. (1994). La función crítica del discurso alienista en De sobremesa de José Asunción Silva. Hispanic Journal, № 15, vol. 1. Indiana: University of Pennsylvania.

»Villanueva Collado, A. (2004). Max Nordau, cultura helénica e inversión sexual en De Sobremesa, de José Asunción Silva. Ciberletras, № 12. Nueva York: Yale University.

»Zola, E. (2002). La novela experimental. En El naturalismo, pp. 41-94. Barcelona: Península. 